\title{
From plants to pharmacy shelf: natural products revival
}

\author{
Milen I. Georgiev
}
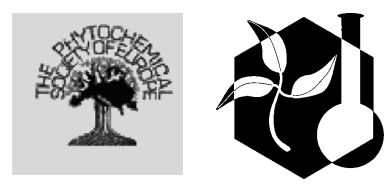

Published online: 5 April 2016

(C) Springer Science+Business Media Dordrecht 2016

Throughout most of history medicinal plants (and their bioactive principles) have long had a central role in the treatment of a wide spectrum of diseases, hence continuously supporting the health of human populations (Cragg et al. 2014; George et al. 2016). Traced back to Paleolithic Age, hunter-gatherer ancestors possessed extensive empirical knowledge (sense experience) on the nutritional and medicinal properties of surrounding vegetation (George et al. 2016).

Nowadays, in excess of quarter of modern medicines are derived either directly or indirectly from plants; moreover in case of cancer therapy and infectious diseases these numbers exceed 60-75\% (Georgiev 2014). According to the Directive 2004/24/EC of the European Parliament and of the Council herbal medicinal product is "any medicinal product, exclusively containing as active ingredients one or more herbal substances or one or more herbal preparations, or one or more such herbal substances in combination with one or more such herbal preparations". De Luca

\section{I. Georgiev ( $\square)$}

Group of Plant Cell Biotechnology and Metabolomics, The Stephan Angeloff Institute of Microbiology, Bulgarian Academy of Sciences, 139 Ruski Blvd., 4000 Plovdiv, Bulgaria

e-mail: milengeorgiev@gbg.bg

\section{I. Georgiev}

Center of Plant Systems Biology and Biotechnology, Plovdiv, Bulgaria et al. (2012) estimated that the most important commercially relevant pharmaceuticals to be derived from plants are valued at over 22 billion euros on an annual basis. Taxol (antineoplastic), galanthamine (reversible cholinesterase inhibitor), codeine and morphine (analgesic) and artemisinin (antimalarial) are amongst the best-selling drugs worldwide. It is worth of mentioning that the discovery of artemisinin (a sesquiterpene lactone, isolated for the first time by prof. Youyou Tu from Artemisia annua L.) was recently awarded with Nobel Prize in Physiology and Medicine 2015 (Efferth et al. 2015). Natural products revival, isn't it?

Recently in the USA, for instance, two new drug applications have been approved for marketing botanical products as prescription drugs, namely Veregen (sinecatechins), a topical drug for the treatment of genital and perianal warts and Fulyzaq (crofelemer), an oral drug for the treatment of HIV/AIDS related diarrhea. These two new drug applications approvals are testimonial examples that new therapies derived from complex botanical mixtures can be developed to meet modern FDA standards of quality, safety, and efficacy as new drugs (Lal 2015).

In October 2015, the Novotel Hotel in Plovdiv (Bulgaria) hosted the 2nd International Conference on Natural Products Utilization: from Plants to Pharmacy Shelf (ICNPU-2015; www.icnpu2015.cim.bg), jointly organized by the Phytochemical Society of Europe (PSE) and its sister society in Bulgaria, the recently 
established Bulgarian Phytochemical Society (BPS). In excess of 330 scientists and exhibitors coming from ca. 50 different countries attended the meeting. The international committee of ICNPU-2015 assembled an exciting program, featuring diverse keynote lectures of Bharat B. Aggarwal (USA), Alisdair Fernie (Germany) and Rob Verpoorte (The Netherlands), consecutively followed by 15 plenary and invited talks, 52 oral presentations and 254 posters. Several awards were kindly provided by the sponsors, i.e. four TEVA awards, Elsevier best poster award, Springer best poster award, CRC best poster award and BPS best poster award. As a tradition, ICNPU meetings focus on the emerging trends in the treatment (and prevention) of malignancies, sustainable (bio)production and use of natural products, and the emerging omics platforms toward accelerated lead finding. This editorial article aims at giving little insight into natural products-related research, presented at the ICNPU-2015 conference.

The importance of traditional medicinal plants is introduced by a set of excellent reviews on Rhodiola rosea (golden root), Saussurea laniceps (snow lotus) and Astragalus species (Fabaceae), their bioactive molecules as well as records of accomplishment in traditional use (Chen et al. 2016; Krasteva et al. 2016; Marchev et al. 2016). The development of modern biotechnological approaches for sustainable supply of high value molecules (Georgiev and Weber 2014) is also outlined.

Further, Luca et al. (2016) highlighted the antigenotoxic potential of dietary flavonoids. Some dietary flavonoids have shown an immense protective effect against DNA damage, induced by different genotoxic agents such as mycotoxins, food processing-derived contaminants, cytostatic agents, other medications (estrogenic and androgenic hormones), metal ions, radiopharmaceuticals and ionizing radiation, and etc. In another excellent review, Koziol and SkalickaWozniak (2016) outlined the pharmacological potential of imperatorin (a furanocoumarin derivate) in the treatment of central nervous system and cardiovascular disorders along with its antineoplastic and antiviral properties. The isolation and purification of imperatorin by means of counter-current chromatography is also nicely covered.

According to Cragg et al. (2014) there is an urgency to discover new drugs and leads for the treatment of infectious disease that are rapidly developing resistance to previously effective drugs. Mikulasova et al. (2016) summarized the potential synergism between antibiotics and natural products (plant extracts and essential oils) with efflux pump inhibitory activity, towards coping with multidrug-resistant staphylococci. Parasitic infections, caused by Leishmania parasites, remain a severe public health problem, especially in developing countries where it is highly endemic. In another comprehensive review, Oliveira et al. (2016) discussed the current knowledge on the marine invertebrate extracts and pure compounds against Leishmania parasites along with the data on structure-activity relationships and possible mechanisms of action.

I am deeply grateful to Rob Verpoorte, Editor-inChief, for his continued support to ICNPU meeting series, and great efforts and tireless exertion in promoting natural products research. An enormous support of the PSE and its President-Prof. Dr. Miroslav Strnad (Institute of Experimental Botany, Olomouc, Czech Republic)—is greatly appreciated.

Looking forward to hosting you again at ICNPU2017 !

\section{References}

Chen Q-L, Chen X-Y, Zhu L, Chen H-B, Ho H-M, Yeung W-P, Zhao Z-Z, Yi T (2016) Review on Saussurea laniceps, a potent medicinal plant known as "snow lotus": botany, phytochemistry and bioactivities. Phytochem Rev. doi:10. 1007/s11101-015-9452-y

Cragg GM, Grothaus PG, Newman DJ (2014) New horizons for old drugs and drug leads. J Nat Prod 77:703-723

De Luca V, Salim V, Atsumi SM, Yu F (2012) Mining the biodiversity of plants: a revolution in the making. Science 336:1658-1661

Efferth T, Zacchino S, Georgiev MI, Liu L, Wagner H, Panossian A (2015) Nobel prize for artemisinin brings phytotherapy into the spotlight. Phytomedicine 22(13):A1-A3

George DR, Edris W, Hanson R, Gilman F (2016) Medicinal plants-the next generation. Lancet 387:220-221

Georgiev MI (2014) Natural products utilization. Phytochem Rev 13:339-341

Georgiev MI, Weber J (2014) Bioreactors for plant cells: hardware configuration and internal environment optimization as tools for wider commercialization. Biotechnol Lett 36:1359-1367

Koziol E, Skalicka-Wozniak K (2016) Imperatorin-pharmacological meaning and analytical clues: profound investigation. Phytochem Rev. doi:10.1007/s11101-016-9456-2

Krasteva I, Shkondrov A, Ionkova I, Zdraveva P (2016) Advances in Phytochemistry, pharmacology and biotechnology of 
Bulgarian Astragalus species. Phytochem Rev. doi:10.1007/ s11101-016-9462-4

Lal R (2015) Botanical drug review. FDA/CDER SBIA Chronicles. November 17

Luca VS, Miron A, Aprotosoaie AC (2016) The antigenotoxic potential of dietary flavonoids. Phytochem Rev. doi:10. 1007/s11101-016-9457-1

Marchev AS, Dinkova-Kostova AT, György Z, Mirmazloum I, Aneva IY, Georgiev MI (2016) Rhodiola rosea L.: from golden root to green cell factories. Phytochem Rev. doi:10. 1007/s11101-016-9453-5
Mikulasova M, Chovanova R, Vaverkova S (2016) Synergism between antibiotics and plant extracts or essential oils with efflux pump inhibitory activity in coping with multidrugresistant staphylococci. Phytochem Rev. doi:10.1007/ s11101-016-9458-0

Oliveira M, Barreira L, Gangadhar KN, Rodrigues MJ, Santos T, Varela J, Custodio L (2016) Natural products from marine invertebrates against Leishmania parasites: a comprehensive review. Phytochem Rev. doi:10.1007/ s11101-016-9455-3 